\title{
Susceptibility Level on Plant Species on the Basis of Air Pollution Tolerance Index in Kanchipuram Town
}

\author{
Sumathi Ramesh ${ }^{\# 1}$ and SriramGopalsamy ${ }^{* 2}$ \\ \#Department of Civil \& Structural Engineering, \\ Sri ChandrasekharendraSaraswathiViswaMahaVidyalaya, Enathur, \\ Kanchipuram - 631 561, Tamilnadu, India \\ 1sumathiram72@gmail.com \\ *Department of Mechanical Engineering, \\ Sri ChandrasekharendraSaraswathiViswaMahaVidyalaya, Enathur, \\ Kanchipuram - 631 561, Tamilnadu, India \\ 2drgsriram@gmail.com
}

\begin{abstract}
Kanchipuram, one of the holiest city is highly polluted in nowadays with smoke, dusts and domestic wastes due to industrialization and urbanization. It is most important to know the quality of air and its impact on the plants in this temple city. Plant species which are tolerant to air pollution are found out by the landscapist by determining the Air pollution tolerance index (APTI). The present research aims to determine the APTI values for five common roadside plant species growing in three different locations in Kanchipuram town, India areSaracaasoca, TerminaliaCatappa, Syzygiumcumini, Thespesiapopulnea,Pongamiaglabra. Thirty numbers of samples were collected from these five plants. The APTI was measured by combining the four various physical and biochemical characteristics such as water content in leaf (RWC), Green colour pigment in leaf (Tch), Ascorbic acid content (AA) and pH value of leaf extraction.. The result from this study shows that Saracaasocais the most tolerant species and the TerminaliaCatappa is the least one.
\end{abstract}

Keywords- Aerosols, Tolerance index, Bio - indicator, Species, Particulate matter

\section{INTRODUCTION}

Pollution is the introduction of contaminants into the natural environment that causes adverse change. Air pollution results from an injection of any contaminants in the form of gases, aerosols and particulate matters by natural or from anthropogenic sources. These pollutants cause adverse effects to man and his environment [1]. Atmospheric air is highly contaminated by human activities, rapid growth of industries, vehicular emission and urbanization [2].

Plants play major role in analyzing and balancing the ecosystem by their active involvement in the biogeochemical cycle such as minerals, $\mathrm{CO}_{2}$ and $\mathrm{O}_{2}$ [3]. Trees are used to remove heavy metals like Cadmium, Nickel, Zinc, Lead etc., and gases from the ambient air. Sensitivity of the species to air pollutants are varying from species to species. More sensitive plant species are used as bio-indicators in air pollution [4].

Plants with broad leaf area are used to reduce the concentration of pollutants in the environment by absorbing and accumulating it on the surface. This absorbing capacity varies from species to species [5]. Plants are affected by air pollutants directly through leaves or indirectly by altering the soil nature. Particulate matter causes the damage to the leaves by closing their stomata thereby reducing their chlorophyll content. Plants when they are exposed to pollutants change their physical characteristics at first and visible markings on the leaf surface at last [6].

Several atmospheric pollution control techniques are existing but cleansing of atmosphere by absorbing gaseous and aerosols through leaves of the plants is one of the best, natural and simplest method[7]. Factors which causes the impacts on the plants are meteorological conditions, concentration of pollutants in the air and their retention time in the atmosphere [8],[9]. Tolerance levels of plants have been tested to determine the level of pollution. APTI values can be determined by the method of analyzing the various parameters such as $\mathrm{pH}$, total chlorophyll content, ascorbic acid and relative water content [10]. Plants showing greater APTI values are considered as high tolerant to atmospheric pollution than those showing lesser values as given in Table I. Species act as bio-indicators of air pollution when they show lesser APTI values. Plant species are arranged in series with their tolerance level to air pollution based on their APTI [11]. 
TABLE I. Result classification of APTI [12]

\begin{tabular}{|c|c|}
\hline APTI & RESPONSE \\
\hline$<1$ & Very sensitive \\
\hline $1-16$ & Sensitive \\
\hline $17-29$ & Intermediate \\
\hline $30-100$ & Tolerant \\
\hline
\end{tabular}

Susceptibility and resisting capacity of the plant species are obtained from their response showing towards air pollution at various levels of their characters [13]. The necessity of planting trees in cities and rural environment is realized that they are very helpful in cleaning the ambient air and make the environment free from pollution [14].The present study is focused to create the awareness about the species and their important role in the reduction of air pollution by natural healing system.

The city of Kanchipuram $\left(12.83^{\circ} \mathrm{N}\right.$ latitude, $79.70^{\circ} \mathrm{E}$ longitude, $83.2 \mathrm{~m}$ (273 ft) above sea level) is located in the Indian State of TamilNadu. The city covers an area of $11.605 \mathrm{~km}^{2}$. The land around Kanchipuram is flat and slopes towards the south and east and falls as one of the seven Tirthas (Pilgrimage sites) in India, it has tourist visitors from all over the country and even from abroad. Kanchipuram is known for its cultural heritage and a tourist attraction [15]. The important sources of pollutants here are from vehicular emission, chimneys in industries and open burning. Totally five common plants such as Saracaasoca, TerminaliaCatappa, Syzygiumcumini, Thespesiapopulnea and Pongamiaglabrafrom three regions in Kanchipuram city were selected for the study.

The study area was divided into three study sites such as Control Point, Heavy Traffic, and Low Traffic for comparing the tolerance level of the collected leaves species growing in different circumstances. Control Point should be a residential area with no traffic, CollectorateHousing Board area was taken as the control site, as there is a very less movement of vehicles, which means pollution will also be less. The CCTV footages collected from the Control room shows the MoongilMandapam is the heaviest traffic area with around 6,50,000 vehicles including Buses, Cars, Trucks, Minibuses, Two-wheelers, Auto-rickshaws flying in a week. This area being the junction for four roads, more vehicles pass by and hence it is taken as Heavy Traffic Point for the Study, (Figure 1). Low Traffic was fixed at Pallavarmedu considering the movement of vehicle, as maximum houses and schools are there in this area it was taken as Low Traffic Point.

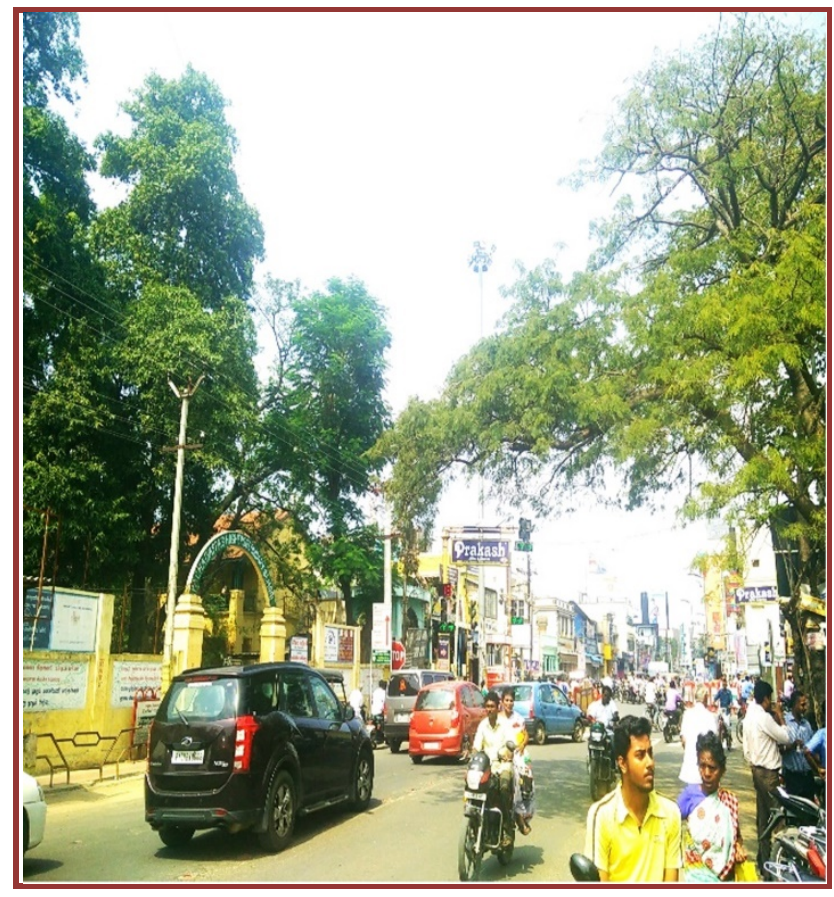

Fig. 1.Thespesia Populnea in Heavy Traffic Area

Locations of the five trees in each of the three sites were located using the GPS tracking device. The locations with Latitude and Longitude were noted down and map was plotted for the same using ARC MAP and ARC CATALOG software. Respective Ward maps under which the locations fall were collected from the Kanchipuram Municipality and plotted on the same map. Control Point falls under Ward No. 45, (Fig.2.), Heavy Traffic area comes under Ward No. 21, 30, (Fig. 3.), Low Traffic area falls under Ward No. 18, 19, (Fig.4.). 


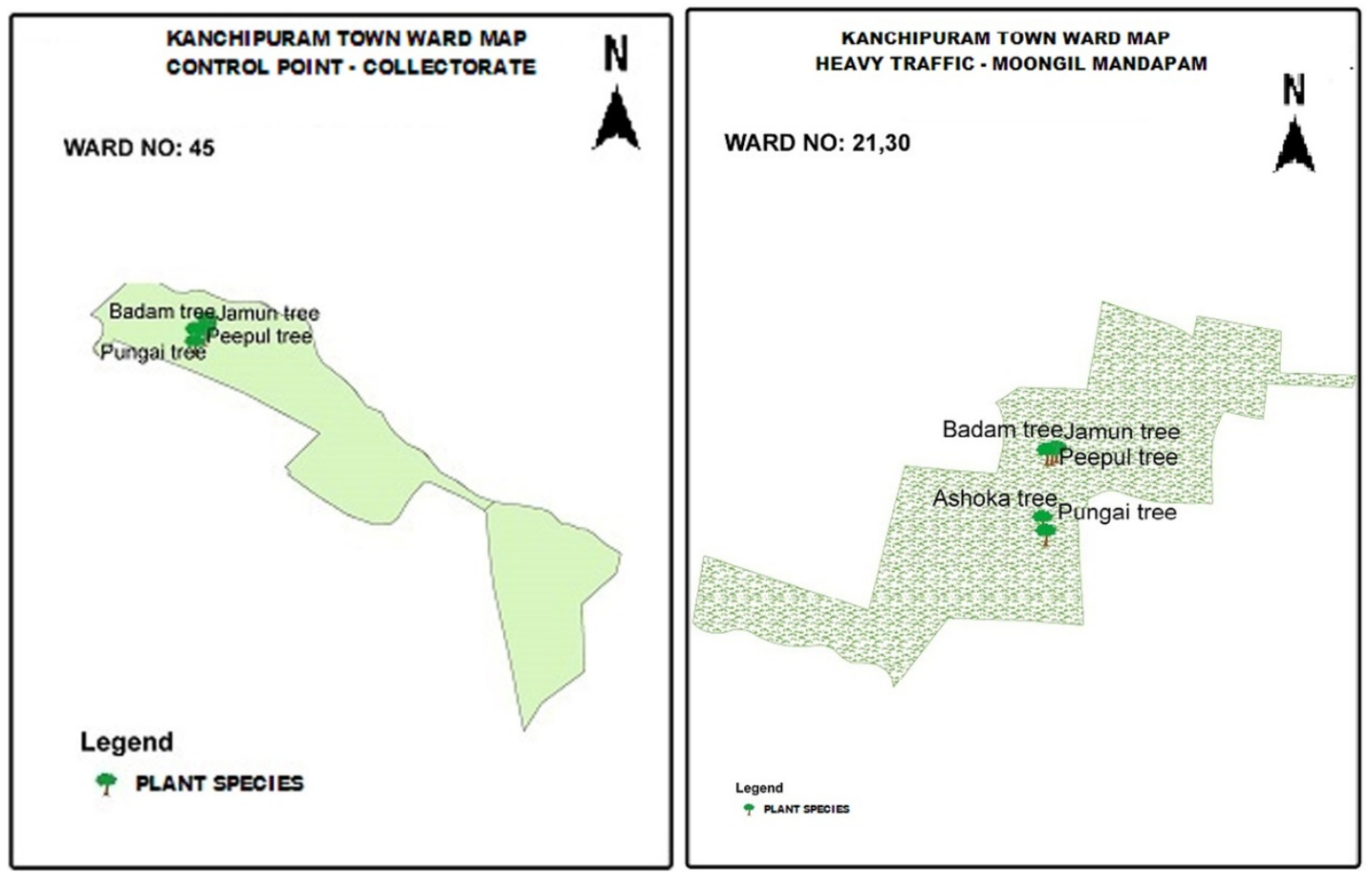

Fig. 2.Ward Map - Control pointFig. 3. Ward Map - Heavy traffic area

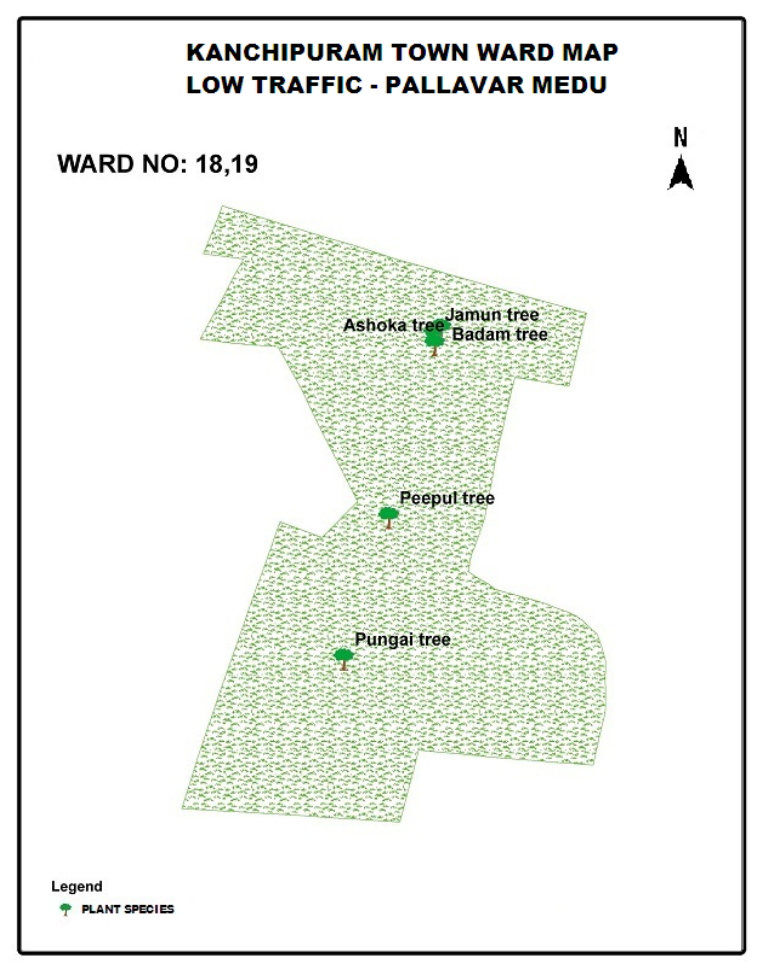

Fig. 4. Ward Map - Low traffic area

\section{A. Sampling}

\section{MATERIALS AND METHODS}

Leaves samples were collected from the respective sites. Fresh leaves were collected from each tree and were put in air-tight zip lock covers. Total of 30 samples were collected, five plant species from each of the three study sites which comprises of 15 samples and from each single species leaves were collected from two different heights such as Low Point and High Point. Low Point is at 1.6m from the ground level and High Point is at $1.95 \mathrm{~m}$ from the ground level [16]. Sampling was done in the early morning between $6.00 \mathrm{a}$.m. and 9.00 a.m. in the month of March. 


\section{B. Methodology}

The collected fresh leaves were then immediately brought to the respective laboratory for testing. The leaves were then analyzed for Ascorbic Acid, pH of leaf extract, Total Chlorophyll content and Relative Water Content by using standard procedure (JyotiKumari and SurinderDeswal' 2017).

The results obtained from the analysis for each of the 30 samples was used for finding the APTI value by using the formula,

$\mathrm{APTI}=\frac{[\mathrm{AA}(\mathrm{TCh}+\mathrm{pH})+\mathrm{RWC}]}{10}$

Where,

$\mathrm{AA}=$ Ascorbic Acid content in mg/g
$\mathrm{TCh}=$ Total chlorophyll in $\mathrm{mg} / \mathrm{g}$
$\mathrm{pH}=\mathrm{pH}$ of leaf extract
RWC = Relative water content of leaf in \%

\section{RESULTS AND DISCUSSION}

Chlorophyll content in plants reduces due to over pollution. Hence plants containing more chlorophyll content show their ability of tolerance to air contaminants. Total chlorophyll content is highest for TerminaliaCatappaat Control Point in the low point height and is least for PongamiaGlabra in Low Traffic in the low point (Table II).

Table II. Total chlorophyll content and relative water content for 30 samples

\begin{tabular}{|c|c|c|c|c|c|c|c|c|c|c|c|c|}
\hline \multirow{3}{*}{ Species Name } & \multicolumn{6}{|c|}{ Total chlorophyll content } & \multicolumn{6}{|c|}{ Relative Water Content } \\
\hline & \multicolumn{2}{|c|}{ Control Point } & \multicolumn{2}{|c|}{ Heavy Traffic } & \multicolumn{2}{|c|}{ Low Traffic } & \multicolumn{2}{|c|}{ Control Point } & \multicolumn{2}{|c|}{ Heavy Traffic } & \multicolumn{2}{|c|}{ Low Traffic } \\
\hline & L.P & H.P & L.P & H.P & L.P & H.P & L.P & H.P & L.P & H.P & L.P & H.P \\
\hline SaracaAsoca & 0.51 & 0.49 & 0.29 & 0.54 & 0.43 & 0.46 & 87.50 & 83.75 & 79.24 & 76.92 & 90.62 & 90.01 \\
\hline TerminaliaCatappa & 3.04 & 1.08 & 0.59 & 1.11 & 0.50 & 0.63 & 59.21 & 65.76 & 85.71 & 83.85 & 59.87 & 58.44 \\
\hline SyzygiumCumini & 0.34 & 0.49 & 0.41 & 0.43 & 0.58 & 0.53 & 82.45 & 86.48 & 72.91 & 74.19 & 92.50 & 82.02 \\
\hline ThespesiaPopulena & 1.09 & 0.65 & 0.83 & 0.60 & 0.52 & 1.87 & 82.97 & 79.38 & 80.27 & 85.21 & 84.33 & 81.46 \\
\hline PongamiaGlabra & 0.20 & 0.34 & 0.40 & 0.38 & 0.16 & 0.34 & 87.27 & 83.92 & 82.14 & 79.26 & 76.27 & 80.21 \\
\hline
\end{tabular}

The value of relative water content is highest for Syzygiumcuminiin Low Traffic at low point and is least for TerminaliaCatappain Low Traffic in the high point (Table II). $\mathrm{p}^{\mathrm{H}}$ of leaf extract is highest for Pongamiaglabra in Low Traffic at low point height and is least for TerminaliaCatappain Control Point in the low point (Table III). Ascorbic Acid content is highest for Saracaasoca in Control Point at high point height and is least for Syzygiumcumini in Low Traffic in the low point (Table III).

Table III. pH of leaf extract and ascorbic acid content for 30 samples

\begin{tabular}{|c|c|c|c|c|c|c|c|c|c|c|c|c|}
\hline \multirow{3}{*}{ Species Name } & \multicolumn{6}{|c|}{ pH of Leaf Extract } & \multicolumn{6}{|c|}{ Ascorbic Acid Content } \\
\hline & \multicolumn{2}{|c|}{ Control Point } & \multicolumn{2}{|c|}{ Heavy Traffic } & \multicolumn{2}{|c|}{ Low Traffic } & \multicolumn{2}{|c|}{ Control Point } & \multicolumn{2}{|c|}{ Heavy Traffic } & \multicolumn{2}{|c|}{ LowTraffic } \\
\hline & L.P & H.P & L.P & H.P & L.P & H.P & L.P & H.P & L.P & H.P & L.P & H.P \\
\hline SaracaAsoca & 5.73 & 5.65 & 5.56 & 5.54 & 5.60 & 5.61 & 0.47 & 0.53 & 0.15 & 0.12 & 0.26 & 0.21 \\
\hline TerminaliaCatappa & 4.63 & 4.72 & 4.73 & 4.65 & 5.18 & 5.15 & 0.37 & 0.24 & 0.26 & 0.43 & 0.35 & 0.28 \\
\hline SyzygiumCumini & 4.81 & 4.63 & 5.13 & 5.18 & 4.97 & 4.98 & 0.15 & 0.09 & 0.25 & 0.31 & 0.09 & 0.25 \\
\hline ThespesiaPopulena & 5.4 & 5.6 & 5.72 & 5.85 & 5.63 & 5.75 & 0.46 & 0.26 & 0.38 & 0.61 & 0.25 & 0.39 \\
\hline PongamiaGlabra & 5.35 & 5.27 & 5.71 & 5.75 & 5.83 & 5.64 & 0.15 & 0.11 & 0.15 & 0.16 & 0.17 & 0.13 \\
\hline
\end{tabular}

APTI values for five species at various levels were determined and given in (Table IV). and (Figure V). APTI is highest for Syzygiumcumini in Low Traffic in the low point height and is least for TerminaliaCatappain Low Traffic in the high point. APTI values were identified as higher in control point in Saracaasoca succeeded by Pongamiaglabra, Syzygiumcumini, Thespesiapopulnea, TerminaliaCatapparespectively. 
Table IV. APTI values for 30 samples

\begin{tabular}{|l|c|c|c|c|c|c|}
\hline \multirow{2}{*}{ Species Name } & \multicolumn{2}{|c|}{ Control Point } & \multicolumn{2}{c|}{ Heavy Traffic } & \multicolumn{2}{c|}{ Low Traffic } \\
\cline { 2 - 7 } & L.P & H.P & L.P & H.P & L.P & H.P \\
\hline Saracaasoca & 9.04 & 8.70 & 8.01 & 7.76 & 9.22 & 9.13 \\
\hline TerminaliaCatappa & 6.20 & 6.71 & 8.71 & 8.64 & 6.18 & 6.01 \\
\hline Syzygiumcumini & 8.32 & 8.70 & 7.43 & 7.59 & 9.30 & 8.34 \\
\hline Thespesiapopulnea & 8.60 & 8.10 & 8.27 & 8.91 & 8.59 & 8.44 \\
\hline Pongamiaglabra & 8.81 & 8.45 & 8.30 & 8.03 & 7.77 & 8.10 \\
\hline
\end{tabular}

For Heavy Traffic APTI values were more in TerminaliaCatappaand then Thespesiapopulnea, Pongamiaglabra, Saracaasoca, Syzygiumcuminirespectively. For Low Traffic APTI values were found to be greater in SaracaAsocafollowed bySyzygiumcumini, Thespesiapopulnea, Pongamiaglabra, TerminaliaCatapparespectively.

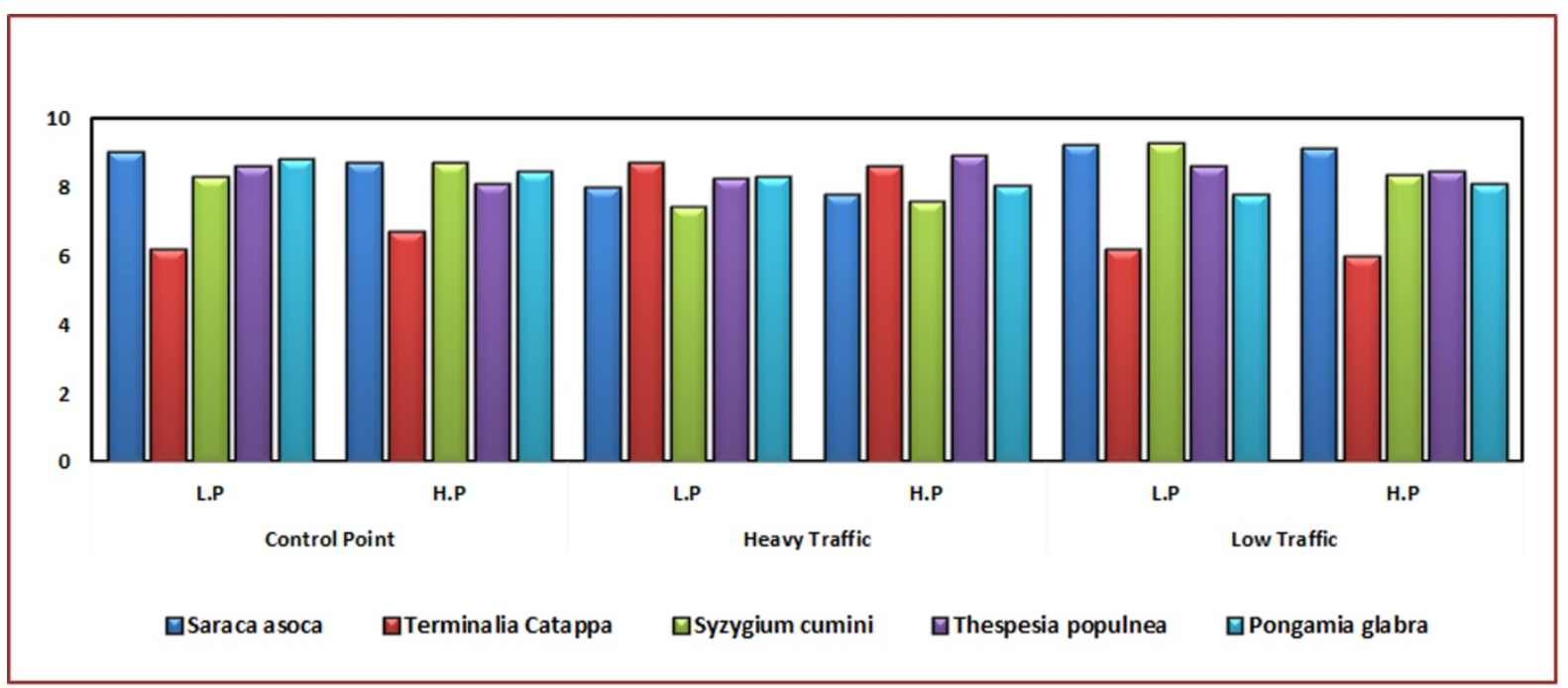

Fig. 5.APTI values for 30 samples

Among the five species Saracaasoca is found to be tolerant in Control Point and Low Traffic, TerminaliaCatappa shows high tolerance in Heavy Traffic and low tolerance in Control Point and Low Point, Syzygiumcumini shows low tolerance in Heavy Traffic, (Table V). and (Fig. 6.).

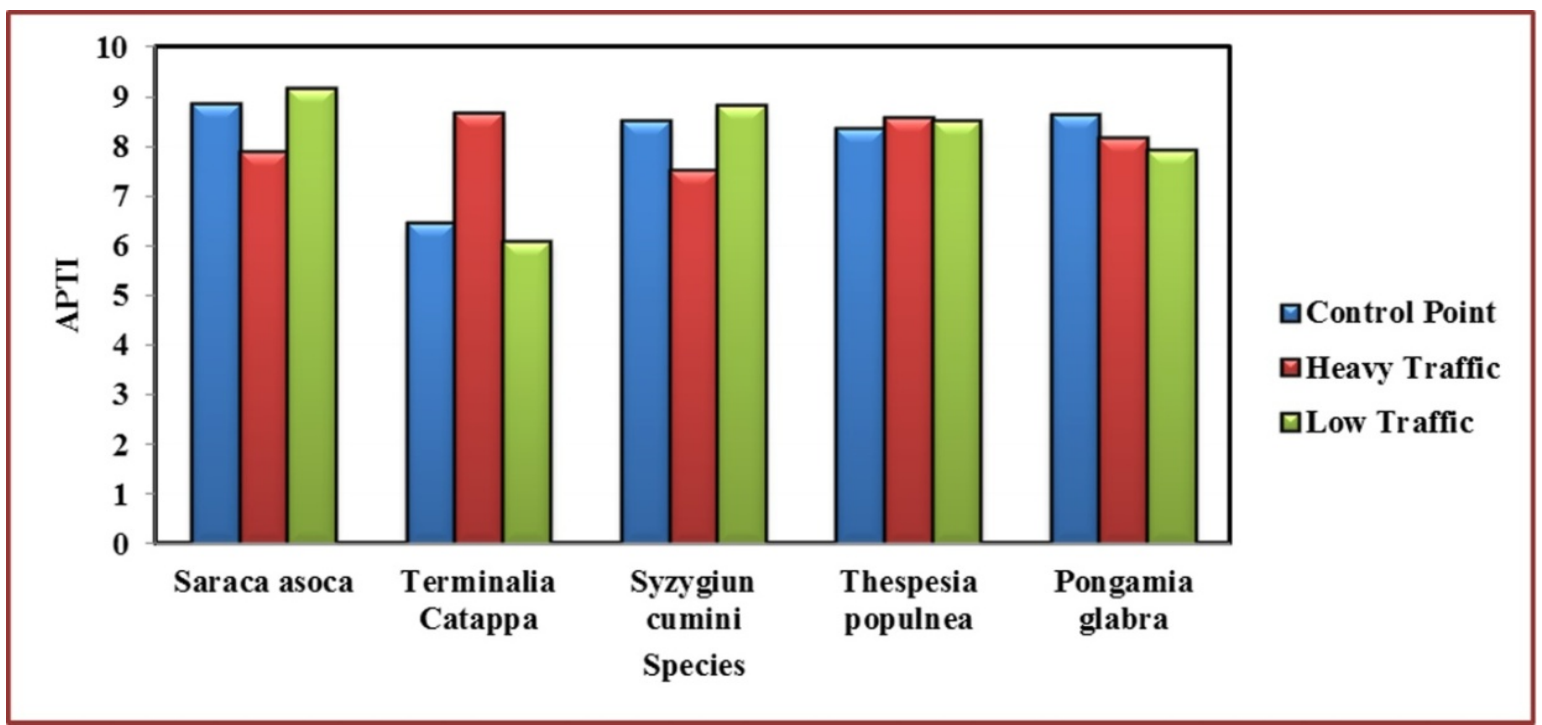

Fig. 6. APTI Mean values for 30 samples 
Table V. Mean APTI values at various levels and its classification

\begin{tabular}{|l|c|c|c|c|}
\hline \multicolumn{1}{|c|}{ Species Name } & Control Point & Heavy Traffic & Low Traffic & Result Classification \\
\hline Saracaasoca & 8.87 & 7.89 & 9.17 & Sensitive \\
\hline TerminaliaCatappa & 6.46 & 8.67 & 6.10 & Sensitive \\
\hline Syzygiuncumini & 8.51 & 7.51 & 8.82 & Sensitive \\
\hline Thespesiapopulnea & 8.35 & 8.59 & 8.51 & Sensitive \\
\hline Pongamiaglabra & 8.63 & 8.17 & 7.93 & Sensitive \\
\hline
\end{tabular}

\section{CONCLUSION}

APTI analysis is more important in view increased growth of industries, urbanization and deforestation. From the above study the APTI vales of five common species collected in three different areas such as control point, heavy traffic and low traffic are obtained. In the low traffic and control point SaracaAsoca is found to be the most tolerant with highest APTI value and TerminaliaCatappa is the least tolerant. In heavy traffic TerminaliaCatappa shows most tolerant than other species.By knowing the values of APTI, it will be very useful to study the absorption capacity of various pollutants. As the APTI values of all the species are between 1 to 16, hence they are sensitive and can be used as indicator for monitoring purposes. Plants which are tolerant are not only used to absorb the heavy metals and also make a green belt for environment.

\section{REFERENCES}

[1] Patience OdafeAgbaire, Rachel OgheneovoOgboru and Emmanuel EyitemiAkporhonor, “Assessment of the Effect of Ambient Air Quality on Some Biochemical Parameters of Trees in three Artificial Forest Reserves in Edo State, Niger Delta, Nigeria,” Asian Journal of Applied Sciences, Vol. 4 ,2014, pp. 696-703.

[2] Geeta and Namrata, "Biochemical studies of some plants affected by air pollution in Jamshedpur, India,”International Journal of Geology, Earth \& Environmental Sciences, Vol. 6, No.3, 2016, pp16-20.

[3] Otuu, Fred Chibuisi, Inya-Agha Stella Ifeoma, Ani, Uchenna Godwin, Ude, C.M, Inya-Agha, and Tochukwu,” Air Pollution Tolerance Indices (APTI) of Six Ornamental Plants Commonly Marketed at "Ebano Tunnel” Floral Market, in Enugu Urban, Enugu State, NigeriaIOSR,” Journal of Environmental Science Toxicology and Food Technology,Vol. 8, 2014, pp. 51-55.

[4] B.T Manjunath and Jayarama Reddy, “Assessment for Variation of Air Pollution Tolerance Index of Selected Plants in Bengaluru Urban,” International JournalofLife Sciences and Scientific Research, Vol. 3, 2017, pp.1522-1526.

[5] DileswarNayak DP, Patel HS, Thakare, K Satashiya and Shrivastava PK, "Evaluation of Air Pollution Tolerance Index of Trees,"Research Environmental Life Sciences,Vol. 8, No.1,2015, pp. 7-10.

[6] Swain, Shradhanjali, Samarendra Narayan Mallick and Pramila Prasad, "Effect of industrial dust deposition on photosynthetic pigment chlorophyll and growth of selected plant species in Kalunga Industrial areas, Sundargarh, Odisha,”International Journal of Botany Studies, Vol.1, 2016, pp. 1-5.

[7] JyotiKumari and SurinderDeswal, “Assessment of Air Pollution Tolerance Index of Selected Plants Unveil to Traffic Roads of Noida, Uttar Pradesh,” International Journal on Emerging Technologies, Vol. 8, 2017, pp.179-184.

[8] Sasmita Das and Pramila Prasad, "Seasonal Variation in Air Pollution Tolerance Indices and Selection of Plant Species for Industrial Areas of Rourkela, India,” Journal EnvironmentalProtection,Vol. 30,2010, pp.978-988.

[9] Aasawari A Tak and UmeshBKakde, “Assessment of Air Pollution Tolerance Index of Plants: A Comparative Study,”InternationalJournal of Pharmacy and Pharmaceutical Sciences, Vol.9 No. 7, 2017, pp. 83-89.

[10] Pradhan AA, Pattanaya SK, Bhadra AK and Ekka K, "Air pollution tolerance index of three tree species along national high way-6 betweenAinthapalli to Remed, Sambalpur District, Western Odisha, India,” International Quarterly Journal of Biology \& Life Sciences.Vol. 4, 2016, pp. 111-120.

[11] SmitaChaudhry and JyotiPanwar, "Evaluation of Air Pollution Status and Anticipated Performance Index of some Tree Species for Green Belt development in the holy city of Kurukshetra, India,’'International Journal for Innovative Research in Science \&Technology, Vol. 2, No. 9,2016, pp. 269-277.

[12] Uma Devi Randhi and M.Anji Reddy, "Evaluation of Tolerant plant species in Urban Environment: A case study from Hyderabad, India,” Universal Journal of Environmental Research and Technology,Vol. 2, 2012, pp.300 - 304.

[13] Chaurasia, Sadhana and Raj Karan, "Study on Air Pollution Tolerance Index of Selected Plant Species along Roadside at Karwi,(UP) India”Journal of Applied Research and Technology, Vol. 1, 2016, pp. 32-38.

[14] R.Bakiyaraj and D.Ayyappan, “Air Pollution Tolerance Index of some terrestrial plants around an Industrial area,”International Journal of Modern Research and Reviews, Vol. 2, 2014,pp. 1-7.

[15] Kanchipuram Details, https://en.wikipedia.org/wiki/kanchipuram

[16] ChouhanAartiIqbalSanjeedaMaheshwari RS and Bafna A, "Study of air pollution tolerance Index of plants growing in PithampurIndustrial area sector 1, 2 and 3”, Research. Journal of Recent Sciences, Vol. 1, 2012,pp.172-177. 